Iranian Journal of Breast

Diseases. 2022; 14(4):62-74.
Original Article

\section{Factors Related to Breast Cancer Preventive Behaviors in Middle-aged Women: An Application of Protection Motivation Theory}

\author{
Hosseini $\mathbf{Z}^{1,2}$, Tavakoli Ghouchani $\mathbf{H}^{3^{*}}$, Mehri $\mathbf{A}^{4}$, Mohaddes Hakak $\mathbf{H R}^{3}$, \\ Lashkardoost $\mathbf{H}^{5}$, Khankolabi $\mathbf{M}^{3}$, Jalambadani $Z^{6}$, Salari $\mathbf{E}^{7}$ \\ ${ }^{1}$ Department of Health Education and Health Promotion, Faculty of Medical Sciences, \\ Tarbiat Modares University, Tehran, Iran \\ ${ }^{2}$ Department of Public Health, Neyshabur University of Medical Sciences, Neyshabur, \\ Iran \\ ${ }^{3}$ Department of Health Education and Promotion, School of Health, North Khorasan \\ University of Medical Sciences, Bojnord, Iran \\ ${ }^{4}$ Department of Health Education, School of Health, Sabzevar University of Medical \\ Sciences, Sabzevar, Iran \\ ${ }^{5}$ Department of Biostatistics and Epidemiology, School of Public Health, North \\ Khorasan University of Medical Sciences, Bojnurd, Iran \\ ${ }^{6}$ Department of Public Health, Torbat Jam Faculty of Medical Sciences, \\ Torbat Jam, Iran \\ ${ }^{7}$ Department of Nursing, School of Nursing and Midwifery, North Khorasan University \\ of Medical Sciences, Bojnourd, Iran
}

Receive: 15/9/2021 Accepted: 30/11/2021

"Corresponding Author: tavakoli_44@yahoo.com

Ethics Approval: IR.NKUMS.REC.1396.60

\begin{abstract}
Introduction: Screening behaviors along with a healthy lifestyle and regular physical activity play an essential role in reducing mortality from breast cancer. The present study aimed to determine the factors associated with breast cancer-preventive behaviors based on the theory of protection motivation in women in Neyshabur city.
\end{abstract}

Methods: In this cross-sectional study, 325 women aged 30 to 69 years referred to Neyshabur health service centers were studied after enrolment through cluster sampling. The data collection tool was a researcher-made self-report questionnaire that had acceptable validity (face and content) and reliability (Cronbach's alpha $=0.83$ ). Data were analyzed using descriptive and analytical statistics with SPSS v19.

Results: Fifty-two percent of participants never had a breast selfexamination before, and $72.6 \%$ had never been to a health center for a clinical breast examination. Only $6.8 \%$ of the participants had regular physical activity. All constructs of conservation motivation theory, except fear, were correlated with breast cancer-preventive behaviors. Perceived self-efficacy had the highest score, and perceived cost had the lowest score among protection motivation theory constructs. Regression analysis reflected that protection motivation, perceived severity, perceived rewards, and awareness were predictors of the adoption of breast cancer-preventive behaviors. Overall, these variables could predict $15.4 \%$ of behavioral change.

Conclusion: Theory-based educational planning to encourage women to adopt breast cancer-preventive behaviors, including a healthy lifestyle and screening behaviors, is essential.

Keywords: Prevention, Breast Cancer, Women, Motivation, Theory 


\section{Introduction}

The annual incidence of breast cancer is increasing by $5.9 \%$ (1). Lifestyle modification through a healthy diet and increasing regular physical activity plays an important role in preventing breast cancer (2). Evidence shows that participation in breast cancer screening programs can reduce the incidence of this disease by up to $40 \%$ (3). The theory of protective motivation focuses on the factors affecting motivation and, ultimately, the protective behavior of the individual (4). Because of the importance of primary and secondary prevention for breast cancer, we aimed to determine factors affecting the adoption of breast cancer prevention behaviors based on the theory of protection motivation in women visiting comprehensive health service centers in Neyshabur.

\section{Materials \& Methods}

This cross-sectional study was conducted on 325 women visiting comprehensive health service centers. The data collection tool was a researcher-made self-report questionnaire including demographic variables, preventive behaviors, and theories of protection motivation theory. The content validity of the questionnaire was examined qualitatively and quantitatively and the Cronbach's alpha value was 0.83 . Data analysis was performed on SPSS 19.

\section{Results}

The mean age of women participating in the study was $37.31 \pm 7.32$ years. Among the participants, 52\% had never performed a breast self-examination, and $72.6 \%$ had never been to a health center for a clinical breast examination. Only $6.8 \%$ of participants had regular physical activity, $49.8 \%$ consumed less than 2 servings of fruit per day, $66.8 \%$ consumed less than 3 servings of vegetables per day, and $39.7 \%$ consumed a combination of solid and liquid oils in their diet. Among the theoretical constructs, the highest score was related to perceived self-efficacy.

Based on the findings, breast cancer prevention behaviors, perceived cost, perceived sensitivity, and perceived reward had a statistically significant relationship with women's education level $(\mathrm{P}<0.05)$. All of the constructs of protection motivation theory, except for fear, were correlated with breast cancer prevention behaviors.

According to the results of the multiple linear regression analysis, protection motivation theory constructs predicted a total of $15 \%$ of the variance in breast cancer prevention behaviors, among which perceived reward, protection motivation, perceived severity, and awareness were the strongest determinants of behavior.

Table 1: Multiple Linear Regression Analysis of the Contribution of Protective Motivation Theory
Constructs to Adopting Breast Cancer-Preventive Behaviors
\begin{tabular}{lcccc}
\hline Variable & Line Slope & Standard Error & P-value & Coefficient R2 \\
\hline Perceived Reward & $-0 / 169$ & $0 / 056$ & $0 / 003$ & \\
Protection Motivation & $0 / 170$ & $0 / 051$ & $0 / 001$ & $0 / 154$ \\
Perceived Severity & $-0 / 098$ & $0 / 037$ & $0 / 008$ & \\
Awareness & $0 / 258$ & $0 / 104$ & $0 / 01$ & \\
\hline
\end{tabular}

\section{Discussion}

In the present study, more than half of the participants had never had a breast selfexamination before, and most of them had never been to a health center for a clinical breast examination. More than half of the participants ate less than 3 servings of vegetables a day. And nearly half of women had less than 2 servings per day of fruit in their food basket. Steinberg et al. reported in their meta-analysis on the effective role of fruits and vegetables in cancer prevention in women (5). Given the importance of a 
healthy diet in the prevention of breast cancer, it seems necessary to develop supportive economic policies for lowincome households.

In our study, less than $10 \%$ of women had regular physical activity. It seems that providing the necessary infrastructure for women's physical activity and educational programs to improve women's motivation and skills in this field will be effective.

The findings of the present study showed that the level of women's education was significantly correlated with breast cancer prevention behaviors and perceived cost, perceived rewards, and perceived sensitivity. These are consistent with the findings of $\mathrm{Al}$ Arawi et al (6). Also, Curtin et al. found that women with lower levels of education were less likely to believe that regular physical activity and a healthy diet were associated with cancer (7). It seems that women with higher levels of education are more aware of breast cancer prevention behaviors; therefore, in planning educational interventions, the educational content should

\section{References}

1. Chin JH, Mansori S. Theory of Planned Behaviour and Health Belief Model: females' intention on breast cancer screening. Cogent Psychol. 2019;6(1):1647927.

2. Dilnaz F, Zafar F, Afroze T, Zakia UB, Chowdhury T, Swarna SS, et al. Mediterranean Diet and Physical Activity: Two Imperative Components in Breast Cancer Prevention. Cureus. 2021;13(8).

3. Seely JM, Alhassan T. Screening for breast cancer in 2018-what should we be doing today? Curr Oncol. 2018; 25(s1):115-24.

4. Bashirian S, Barati M, Mohammadi Y, Moaddabshoar L, Dogonchi M. An application of the protection motivation theory to predict breast self-examination behavior among female healthcare workers. Eur J breast Heal. 2019; 15(2):90.

5. Steinberg J, Yap S, Goldsbury D, NairShalliker V, Banks E, Canfell K, et al. Large- be adjusted to the level of education of the audience.

Based on the findings of our study, the constructs of protective motivation, perceived reward, perceived severity, and awareness were the most important determinants of breast cancer prevention behaviors among women, which accounted for a total of $15 \%$ of the variance in behavior change. Educational programs will be effective in promoting women's skills in achieving protective behaviors.

\section{Conclusion}

Cancer prevention behaviors in women are less than the recommended values. It is necessary to provide theory-based educational programs to improve the selfefficacy and motivation of women along with developing their skills and creating the necessary infrastructure in this field.

scale systematic analysis of exposure to multiple cancer risk factors and the associations between exposure patterns and cancer incidence. Sci Rep. 2021; 11(1):1-14.

6. Arawi A, Ahmed W, Shaman A, Salamh U, Albalawi WAM, Siddhachettiar PA, et al. Association of Demographic Variables with the Awareness of Type 2 Diabetes Mellitus Patients (T2DM) among the Northwest Population in Saudi Arabia. J Diabetes Res. 2020; 2020.

7. Curtin KD, Thomson M, Nykiforuk CIJ. Who or what is to blame? Examining sociodemographic relationships to beliefs about causes, control, and responsibility for cancer and chronic disease prevention in Alberta, Canada. BMC Public Health. 2021; 21(1):1-12. 


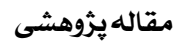 \\ عوامل مرتبط با رفتار هاى يشكَيرىكننده از سرطان يستان در زنان \\ فصلنامه بيمارى هاى يستان ايران \\ ميانسال: كاربردى از تئورى انكيزش محافظت \\ $1 \varepsilon \cdot \cdots ! \mid \varepsilon(\varepsilon): \pi r-V \varepsilon$}

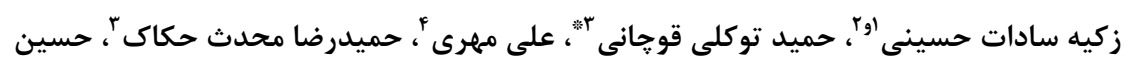

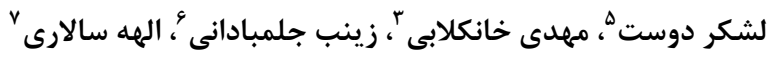

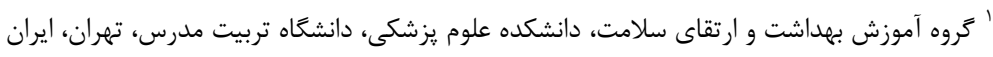

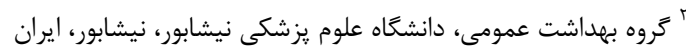

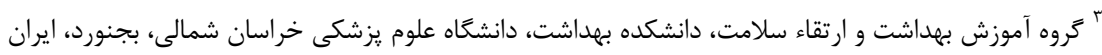

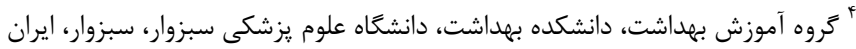

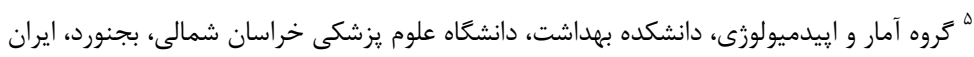

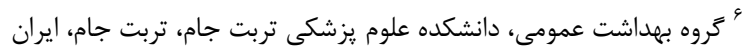

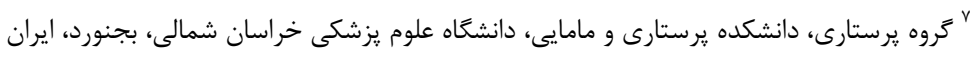

جكيده

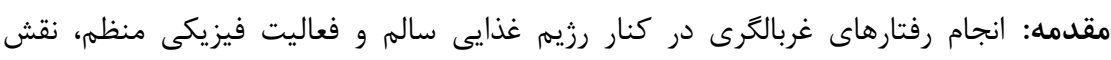

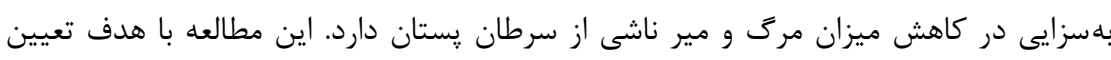

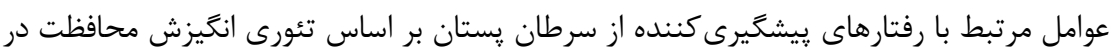
زنان شهر نيشابور انجام شد.

روش بررسى: در اين مطالعه به صورت مقطعى، تعداد هrr نفر از زنان •r تا و 9 ساله مراجعه

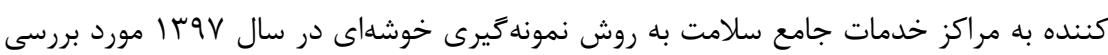

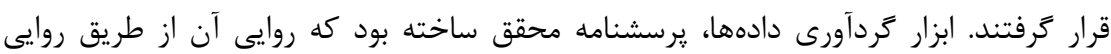

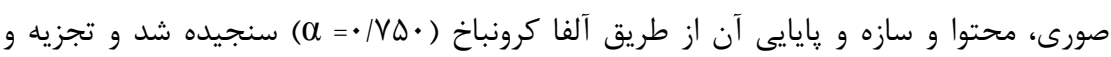

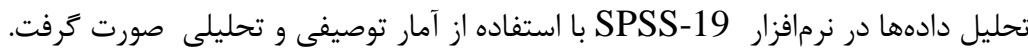

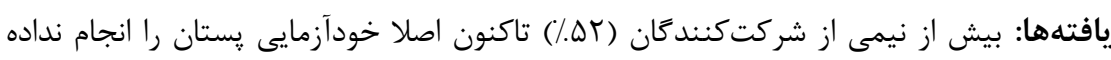

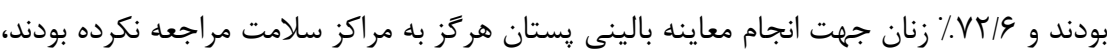

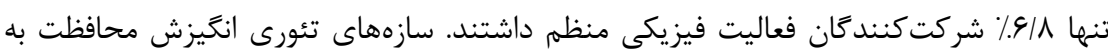

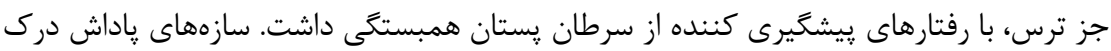

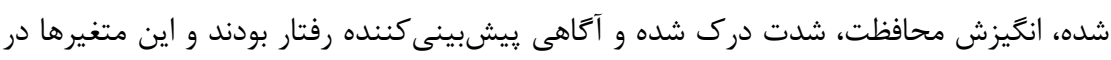

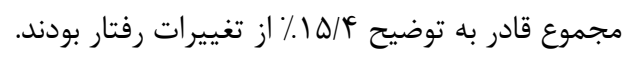
نتيجهكيرى: انجام برنامهريزىهاى آموزشى تئورى محور در راستاى اتخاذ استراتثىهاى

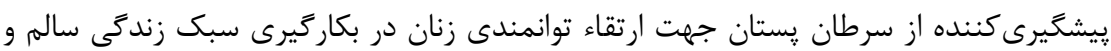
رفتارهاى غربالترى ضرورى است. وازههاى كليدى: تئورى انگيزش محافظت، ييشخيرى، سرطان پستان، زنان

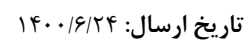

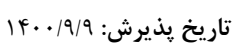

"نويسنده مسئول: tavakoli_44@yahoo.com 
همكاران در مطالعات خود اهميت اين تئورى را در تعيين

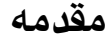

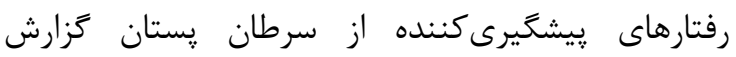

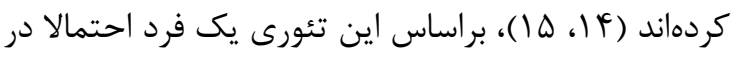
صورتى رفتارهاى پيشگيرى كننده از سرطان يستان را لران انجام مىدهد كه معتقد باشد مستعد ابتلا به سرطان ֶستان است (حساسيت درك شده)، بيمارى براى او جدى و خطرناك است (شدت درك شده)، ياداشهاى درونى و بيرونى كمترى از رفتارهاى موجود كه خطر سرطان يستان را افزايش مىدهند، داشته باشد (ياداش درى لهرى شده)، فرد باور داشته باشد كه ياسخ سازگًار مىتواند خطر

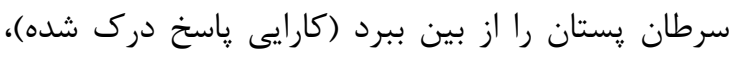

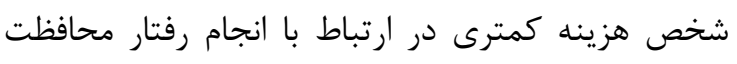

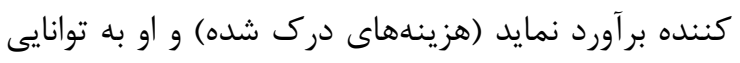
خود جهت انجام موفقيتآميز رفتار محافظتى ايمان داشته باشد (خودكارآمدى درى شده) تا در نهايت به رفتار

ييشَّيرى كننده از سرطان بِتان منجر شود (1).

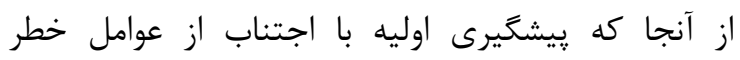
شناخته شده و ييشخيرى ثانويه با روشهاى مختلف

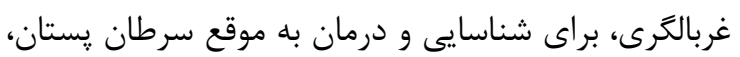

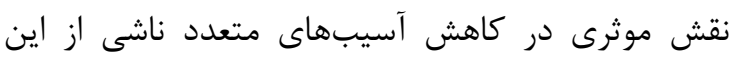
بيمارى در ميان زنان دارند، و با توجه به اهميت انجام رفتارهاى ييشگيرى كننده اوليه نظير فعاليت فيزيكى منظم، مصرف ميوه و سبزى در كنار رفتارهاى پيشگيرى كننده ثانويه از سرطان يستان نظير انجام خودآزمايى ڤستان و معاينه بالينى ڤِتان در زنان ميانسال، مطالعه حاضر با هدف تعيين عوامل مرتبط با

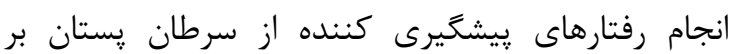

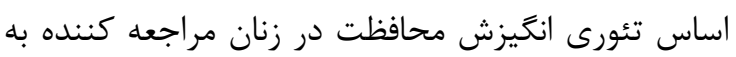
مراكز خدمات جامع سلامت شهر نيشابور انجام شد.

\section{مواد و روشها}

مطالعه حاضر از نوع مقطعى بود. جمعيت مورد مطالعه،

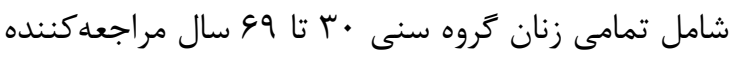
به مراكز خدمات جامع سلامت شهر نيشابور بود. حجم

عليرغم קيشرفت هاى شكرف در زمينه يزشكى در جند دهه كذشته و بهبود قابل ملاحظه در درك علائم و عوامل ايجاد كننده سرطان يستان، اين بيمارى همجنان در در

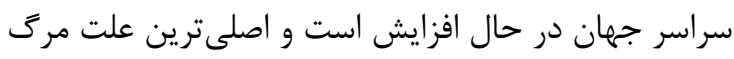
در بين سرطانهاى زنان به شمار مىرود ( (1)، ميزان بروز

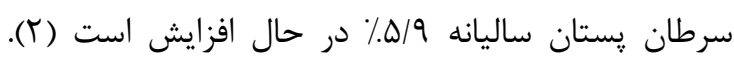

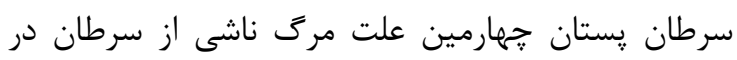

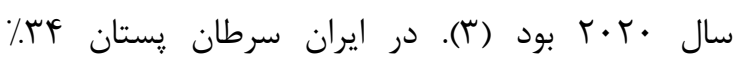

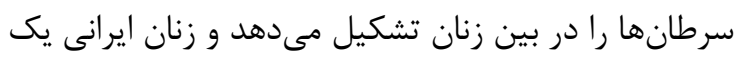

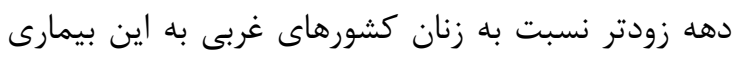

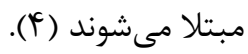

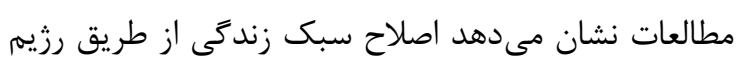

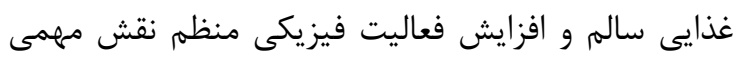

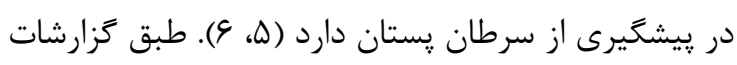

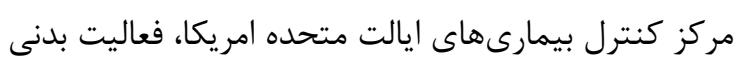

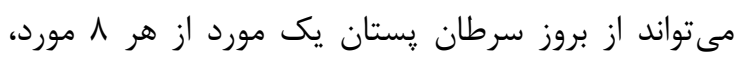

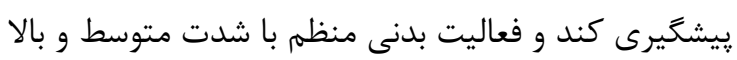

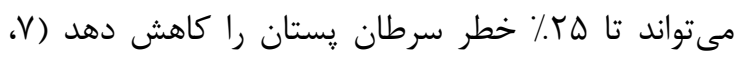
A). شواهد نشان مىدهد كه مشاركت در برنامههاى

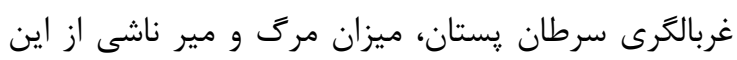

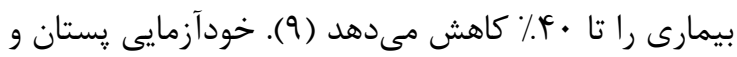
معاينه بالينى پستان از روشهاى تشخيص ارزان و موثر

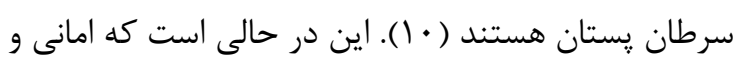

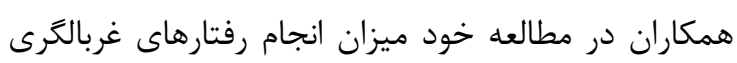

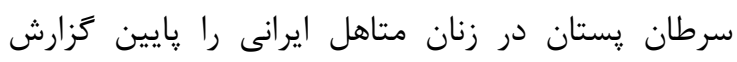

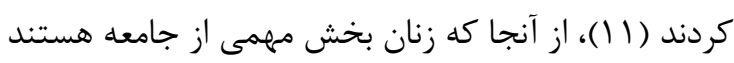

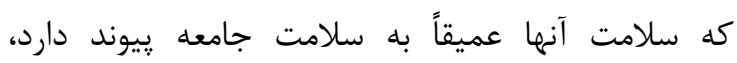

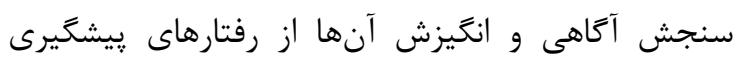

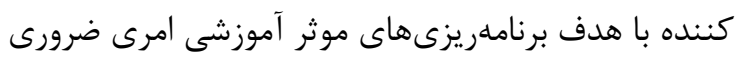

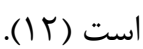
يكى از تئورىهايى كه براى بررسى عوامل موثر بر انگَيزه و

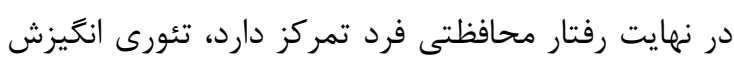

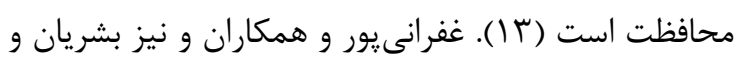


در نظر كرفته شد، در بخش انجام معاينه بالينى پِستان،

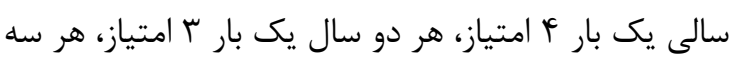

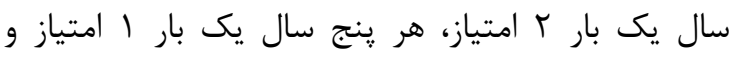

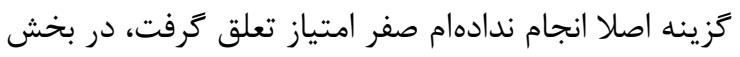
انجام رفتار فعاليت فيزيكى به كزينه هميشه f امتياز،

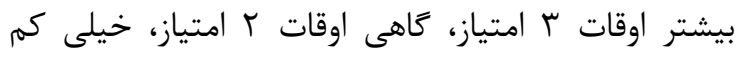
1 امتياز و اصلا صفر امتياز در نظر كرفته شد، در بخش رفتار مصرف ميوه، كزينه هركز صفر امتياز، كمتر از ب

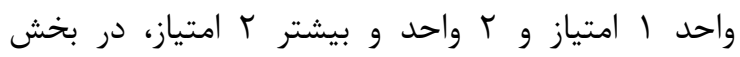
ارزيابى رفتار مصرف سبزى به ززينه هركز، صفر امتياز،

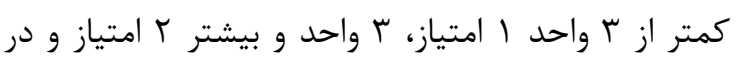
بخش سنجش نوع روغن مصرفى، به كزينه روغن جامد و

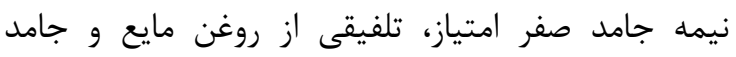

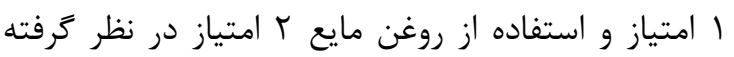
شد. در بخش سوم :رسشنامه سوالات آكاهى با تعداد

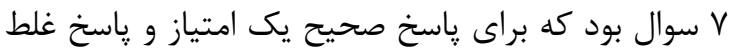

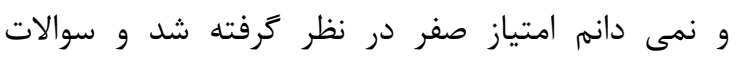
سازههاى تئورى انخيزش محافظت مشتمل بر سوالات

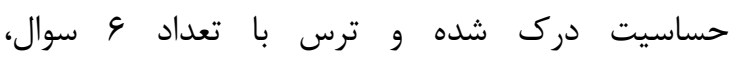
خودكارآمدى درى شده و كارآيى گِاسخ درى شده ياداش درك شده تعداد f سوال و هزينه درك شده،

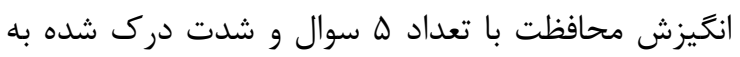

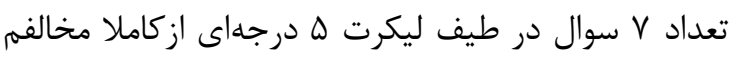
تا كاملا موافقم با امتياز يك تا ينج نمرهگذارى شد. درصد نمره كسب شده در هر يك از سازهها از طريق محاسبه تفاضل ميانگين از حداقل نمره هر سازه تقسيم بر تفاضل

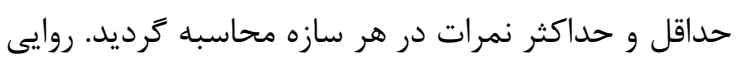
محتواى يرسشنامه به دو صورت كيفى و كمى بررسى شد.

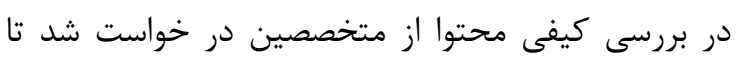

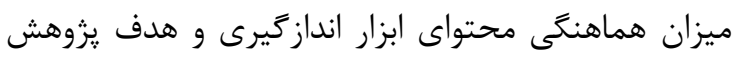
را مورد بررسى قرار دهند و اصلاحات لازم در يرسشنامه هئه

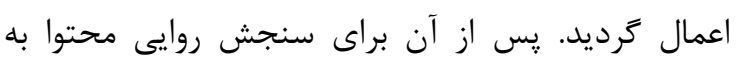

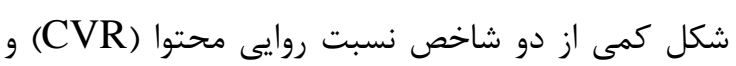

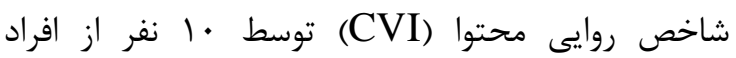

نمونه با توجه به مطالعه مشابه قبلى و با در نظر گرفتن

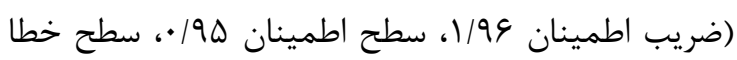

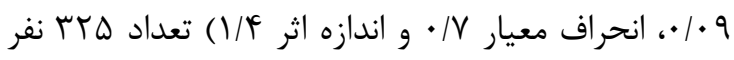
محاسبه شد (IV). نمونه يذيرفت كه جهت از بين بردن اثر مخدوش كننده عوامل اقتصادى، فرهنگى و اجتماعى روى متغيرهاى مورد بررسى، ابتدا 11 مركز خدمات جامع سلامت به لحاظ محل قرارگيرى جغرافيايى به سه منطقه شمال شهر، جنوب شهر، مركز شهر دستهبندى شدند، سيس از ميان مراكز خدمات جامع سلامت در هر يك از نقاط شمال شهر، مركز شهر و جنوب شهر در مجموع 9 مركز بهطور

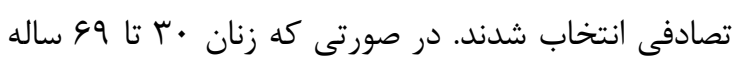

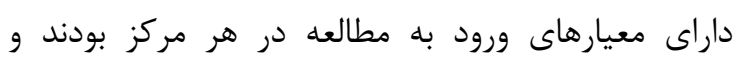

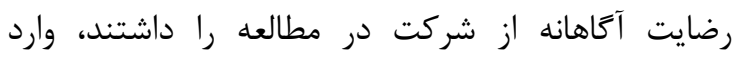

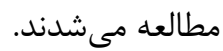
معيارهاى ورود به اين مطالعه، سواد خواندن و نوشتن، مُدل، عدم ابتلاى فرد به بيمارىهاى خوش خيم يا بدخيم

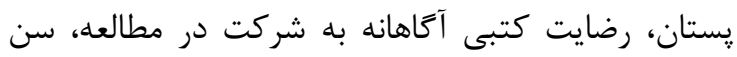
بالاتر از • ب سال و ساكن بودن در شهر نيشابور بود. زنان

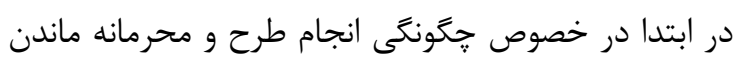
اطلاعات توجيه شدند و فرم رضايتنامه كتبى را تكميل نمودند. يزوهش حاضر يس از تصويب در كميته اخلاق

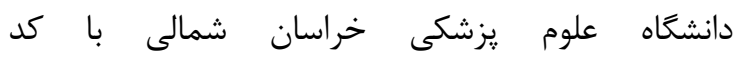
اخلاق IR.NKUMS.REC.1396.60 انجام يذيرفت. ابزار گَردآورى اطلاعات، يرسشنامه محقق ساخته بودكه به

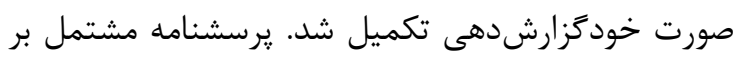
دو بخش بود: بخش اول مربوط به متغيرهاى جمعيت

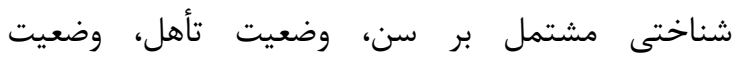
تحصيلات، وضعيت شغل، نوع بيمه درمانى و سابقه

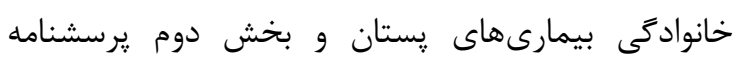

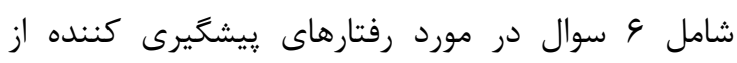

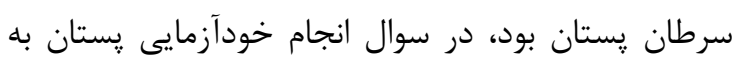

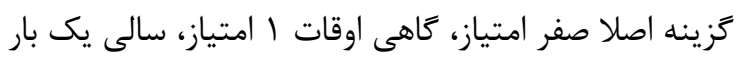

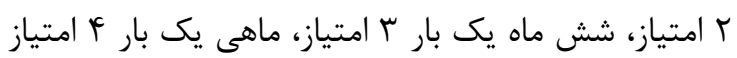


خدمات جامع سلامت جهت انجام معاينه بالينى يستان

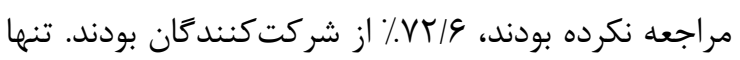

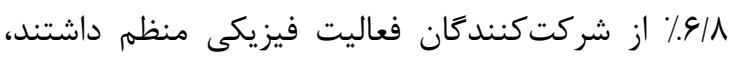

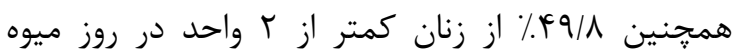

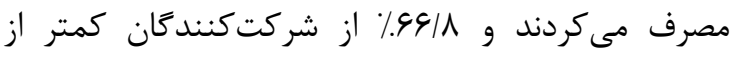
r واحد در روز از سبزيجات استفاده مى كردند و زنانى كه تلفيقى از روغنهاى جامد و مايع در رزيم غذايى خود

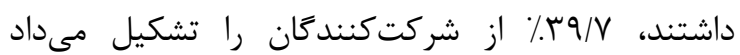

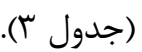

جدول ا: توزيع فراوانى و درصد متغير هاى دموكرافيك شركت كنندَان در مطالعه

\begin{tabular}{|c|c|c|c|}
\hline درصد & تعداد & & متغير \\
\hline$r / V$ & IT & مجرد & \\
\hline $9 r / 9$ & $r \cdot r$ & متاهل & \\
\hline $1 / \Delta$ & $\Delta$ & مطلقه & \\
\hline $1 / 1$ & 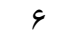 & بيوه & \\
\hline$\Lambda V / I$ & rᄉr & خانهدار & \\
\hline$\Delta / \omega$ & 11 & كارمند & \\
\hline$r / \Delta$ & $\Lambda$ & كارگر & \\
\hline$p / q$ & 19 & آزاد & \\
\hline rq/f & ITA & ابتدايى & \\
\hline & 119 & دبيرستان & تحصيلات \\
\hline$T F /$. & V^ & دانشخاهى & \\
\hline $1 \cdot 10$ & re & دارد & سابقه خانوادگى \\
\hline $19 / 0$ & (9) & 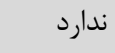 & بيمارىهاى يستان \\
\hline$\Lambda \xi / T$ & rᄉ. & دارد & A \\
\hline IT/A & $F \Delta$ & 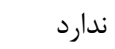 & بيمه \\
\hline
\end{tabular}

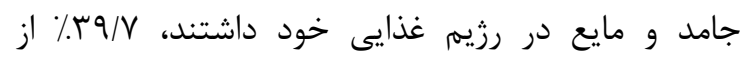

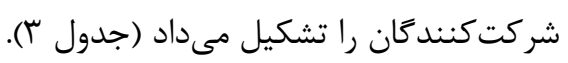

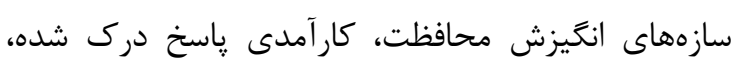

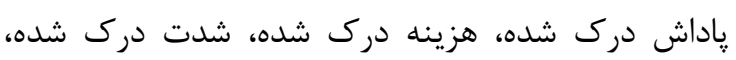

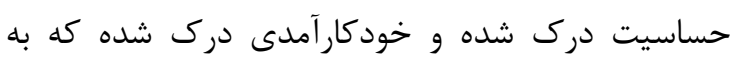
عبارتى باور زنان به توانايى خود جهت انجام رفتارهاى

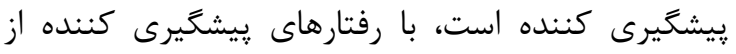
سرطان يستان كه شامل خود آزمايى گِّتان، معاينه بالينى يستان، فعاليت فيزيكى، مصرف ميوه و سبزى و نوع

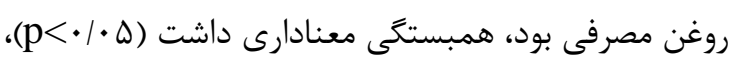

متخصص (1 نفر متخصص آموزش بهداشت و ارتقاى سلامت و r نفر كارشناس ارشد مامايى) مورد بررسى قرار

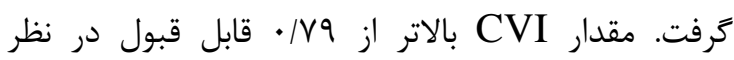
كرفته شد كه در يرسشنامه مذكور 99/.محاسبه كرديد. براى تعيين روايى صورى، يرسشنامه اصلاح شده در يك

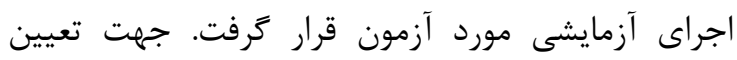
״ايايى، يرسشنامه اصلاح شده بين ·r نفر از گروه هدف توزيع شد و يس از خردآورى و استخراج دادهها مقدار

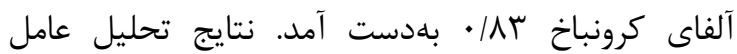
اكتشافى حاكى از حضور تمام عوامل مقياس در جامعه

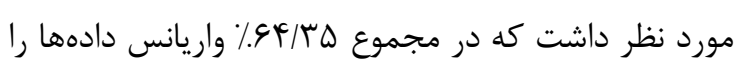
تبيين نمودند و سطح تمام بارهاى تحليل عاملى بزركتر از

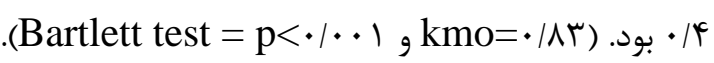

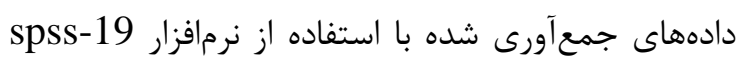
از طريق آمار توصيفى (توزيع فراوانى، ميانخين، انحراف

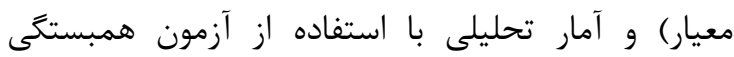

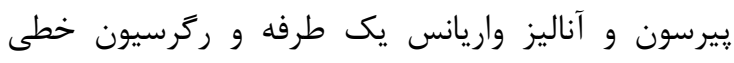
جندكانه مورد تجزيه و تحليل قرار كفت. سطح اطمينان

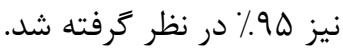

\section{كافتهها}

ميانكين سنى زنان شركت كننده در مطالعه

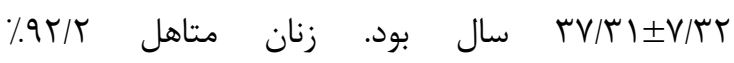
شركت كنندگان را تشكيل دادند و شغل اكثر آنها خانهدار بود، از بين زنان شركت كننده در مطالعه \&|\&r. تحصيلات

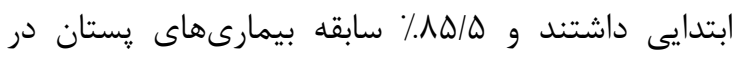

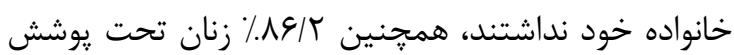
بيمه درمانى بودند (جدول () ). در ميان سازهاى تئورى، بيشترين امتياز كسب شده

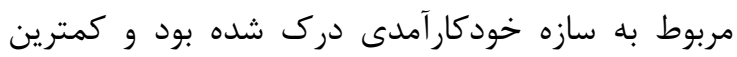
امتياز را هزينه درى شده ناشى از انجام رفتارهاى

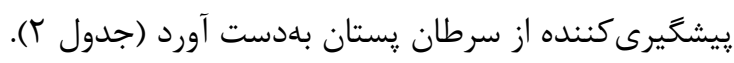

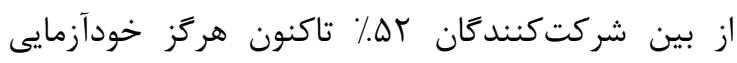
يستان را انجام نداده بودند و زنانى كه اصلا به مراكز 


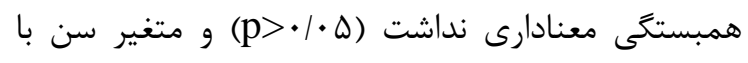

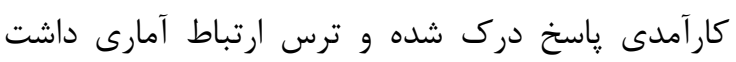

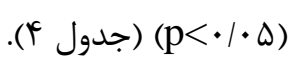

ياداش درى شده با كليه سازمهاى تئورى انخيزش

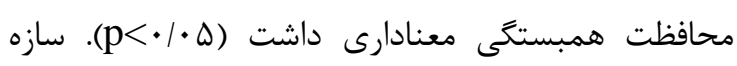
ترس بجز با سازه ياداش درك شده، هزينه درك شده و ماند

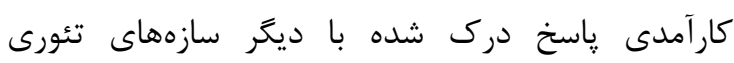

جدول r: توزيع ميانگين و درصد نمرات سازههاى تئورى انگَيزش محافظت

\begin{tabular}{|c|c|c|c|c|}
\hline درصد نمره كسب شده & محدوده نمره & ميانگَين 土 خطاى استاندارد & تعداد سؤالات (N) & 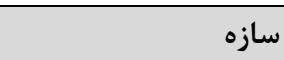 \\
\hline V^ & $r \cdot-r^{r}$ & $19 / \Delta \Delta \pm r / F \Lambda$ & $r$ & خودكار آمدى \\
\hline vi & $r \Delta-\Delta$ & $19 / r \cdot \pm r / r r$ & $\Delta$ & انكَيزش محافظت \\
\hline rv & $r \Delta-\Delta$ & $|r / F| \pm r / \Lambda r$ & $\Delta$ & هزينه درى شده \\
\hline Ve & $r \cdot-r^{f}$ & $19 / r \Lambda \pm r / 0$. & r & كارايى هاسخ درك شده \\
\hline fq & $r \cdot-r$ & $\| / M \pm r / F r$ & f & ياداش درى شده \\
\hline$\Delta \Delta$ & $r \cdot-\varphi$ & $r \cdot / r T \pm \Delta / r \Lambda$ & 4 & ترس \\
\hline 90 & $r \Delta-\gamma$ & $r \Delta / F) \pm \Delta / \Delta r$ & $\checkmark$ & شدت درك شده \\
\hline \& & $r \cdot-\varphi$ & $r / / r \cdot \pm r / 19$ & 4 & حساسيت درك شده \\
\hline 99 & $V_{-} \cdot$ & $F / \Lambda F \pm 1 / \Lambda r$ & v & آكَاهى \\
\hline
\end{tabular}

\begin{tabular}{|c|c|c|c|}
\hline درصد & فراوانى & & متغير \\
\hline$\cdot / \Delta T$ & 199 & اصلا & \\
\hline$r q / T$ & $\Lambda \Delta$ & كاهى اوقات & \\
\hline$V / F$ & TY & سالى يك بار & خود آزمايى يستان \\
\hline$V / I$ & r & و ماه يك بار & \\
\hline$V / \mathcal{A}$ & tr & ماهى يك بار & \\
\hline$V T / Q$ & THE & اصلا & \\
\hline$V / I$ & r & هر ه سال يك بار & \\
\hline $9 / T$ & $r \cdot$ & هر ب سال يك بار & معاينه بالينى يستان \\
\hline$f / 9$ & 10 & هر r سال يك بار & \\
\hline $9 / \Delta$ & r ( - l & سالى يك بار & \\
\hline $\mid r / \Lambda$ & Fa & اصلا & \\
\hline$r T / Q$ & V & خيلى كم & \\
\hline rN/A & Ird & كاهى اوقات & فعاليت فيزيكى \\
\hline $1 N / \Delta$ & 4. & بيشتر اوقات & \\
\hline $9 / 1$ & tr & هميشه & \\
\hline $9 / 1$ & rt & هركز & \\
\hline$\uparrow q / \wedge$ & IET & كمتر از r واحد در روز & مصرف ميوه \\
\hline$r \cdot / r$ & $|r|$ & r واحد بيشتر در روز & \\
\hline $1 \Delta / V$ & DI & هركز; & \\
\hline $99 / 1$ & tiv & كمتر از ب واحد در روز & مصرف سبزيجات \\
\hline $\mid V / \Delta$ & $\Delta V$ & بيشتر از ب واحد در روز & \\
\hline$r \Delta / \Delta$ & ᄉr & جامد ج ج & \\
\hline ५ // & 149 & تلفيقى از جامد و مايع & نوع روغن مصرفى \\
\hline$r F / \Lambda$ & ir & مايع & \\
\hline
\end{tabular}


جدول f: همبستكى سن، سازههاى تئورى انكَيزش محافظت و رفتارهاى بيشغَيرى كننده از سرطان بستان
3 震

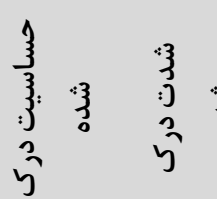
$\begin{array}{lll}2 & \frac{3}{43} \\ 3 & 3 & 3 \\ 3 & 3\end{array}$

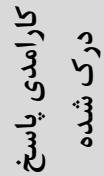

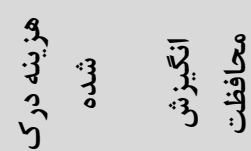
年

داشت و در سازه پاداش درك شده نيز بين زنان با

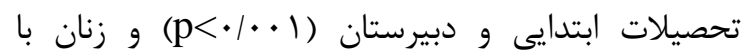
تحصيلات ابتدايى و دانشخاهى (1 ..|•>p) ارتباط آمارى معنادارى وجود داشت.

طبق نتايج تحليل ركرسيون خطى جندأنانه سازههاى

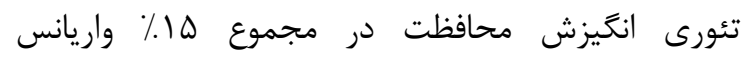

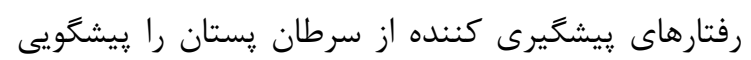

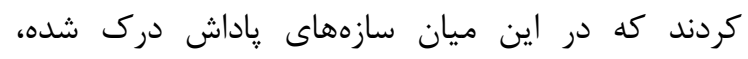

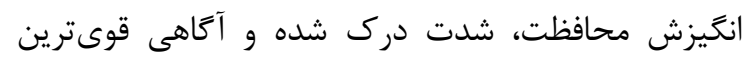
تعيين كننده رفتار بودند.
نتايج آزمون آناليز واريانس يك طرفه نشان داد، انجام رفتارهاى پِيشگيرى كننده از سرطان يستان بين زنان با

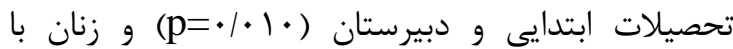

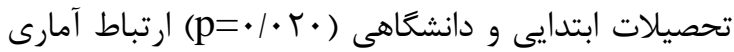
معنادارى وجود داشت، همجنين در سازه هزينه درك شده

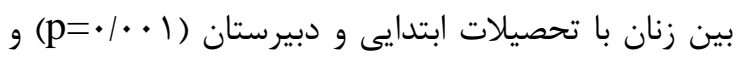

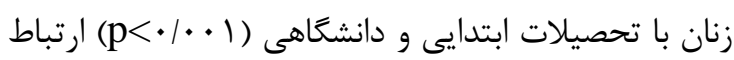
آمارى معنادارى وجود داشت، نتايج اين آزمون نشان داد

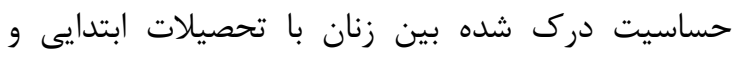
دبيرستان (1) (p=|•) و زنان با تحصيلات ابتدايى و

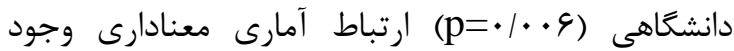


جدول ه: تحليل ركر سيونى خطى جندكًانه سازهاى تئورى انغَيزش محافظت در اتخاذ رفتارهاى يِيشَيرى كننده از سرطان يستان

\begin{tabular}{|c|c|c|c|c|}
\hline ضريب تبيين R & سطح معنادارى & خطاى استاندارد & شيب خط & متغير \\
\hline \multirow{4}{*}{$\cdot / \mid \Delta F$} & $\cdot 1 \cdot r$ & $\cdot / \cdot \Delta q$ & -.1199 & ياداش درك شده \\
\hline & $\cdot 1 \cdot \cdot 1$ & $\cdot|\cdot \Delta|$ & $\cdot / 1 \mathrm{~V}$ & انخَيزش مححافظت \\
\hline & $\cdot / \cdot \wedge$ & $\cdot / \cdot r V$ &.$- \cdot 1 \cdot 91$ & شدت درك شده \\
\hline & $\cdot 1 \cdot 1$ & $\cdot 11 \cdot f$ & $\cdot / r \Delta \Lambda$ & آكاهى \\
\hline
\end{tabular}

نتايج يزوهش ما نشان داد كمتر از • (٪ زنان شركت كننده در مطالعه به طور منظم فعاليت فيزيكى دارند. همسو با اين يافته رمضانى و همكاران در يزوهش خود

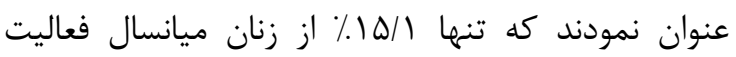
فيزيكى منظم داشتند كه مواردى همجون نداشتن زمان

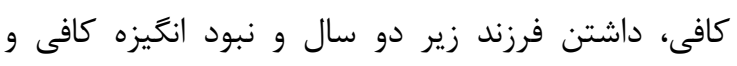
محدوديتهاى يزشكى از قبيل كمردرد را مهمترين موانع خود در عدم انجام فعاليت فيزيكى منظهم بر شمردند (ب (Y)، بهنظر مىرسد فراهم نمودن زير ساختهاى لازم جهت

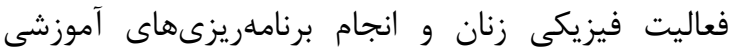
جهت ارتقاء انخيزش و مهارت زنان در اين زمينه موثر خواهد بود. خودكارآمدى درك شده بيشترين امتياز را در بين

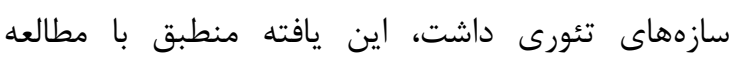
درويش يور و همكاران بر روى رفتارهاى غربالكرى سرطان

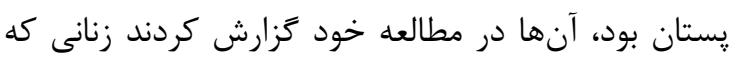

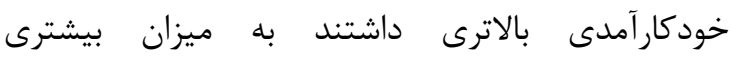

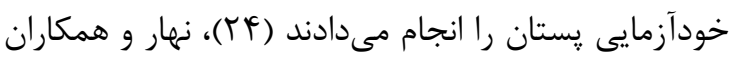
نيز خودكارآمدى را مههترين سازه در انجام رفتارهاى

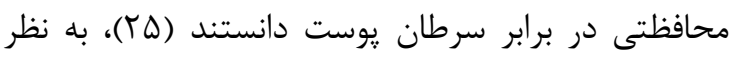

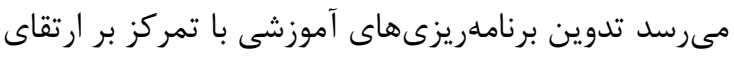

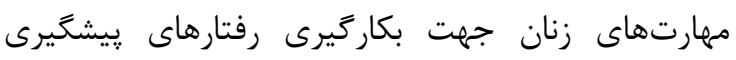
مى تواند نقش بهسزايى دراين زمينه داشته باشد. نتايج مطالعه، حاكى از همبستخى معنادار كليه سازههاى

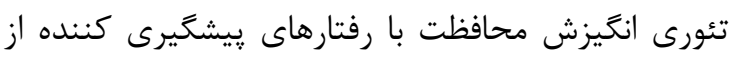
سرطان يستان در زنان شركت مكننده در مطالعه بود.

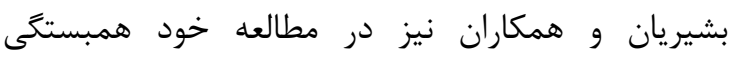

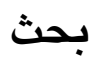
هدف از مطالعه حاضر، بررسى عوامل مرتبط بر انجام رفتارهاى پِيشگيرى كننده از سرطان يستان بر اساس

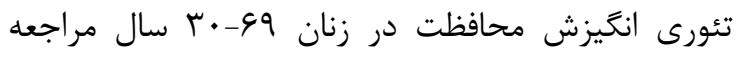
كننده به مراكز خدمات جامع سلامت شهر نيشابور بود. در مر دران مطالعه حاضر بيش از نيمى از زنان مشاركت كننده در يزوهش تاكنون هركز خودآزمايى يستان انجام نداده بودند

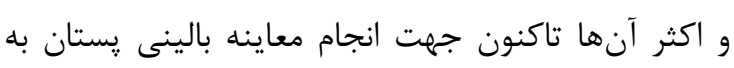

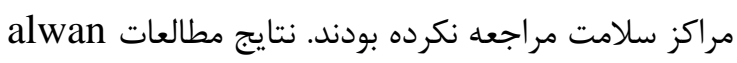

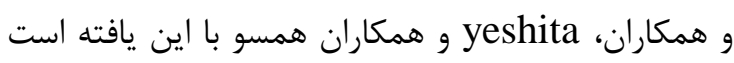

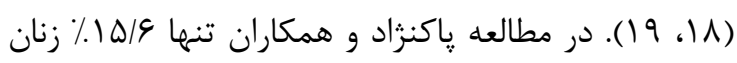

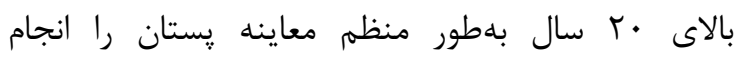

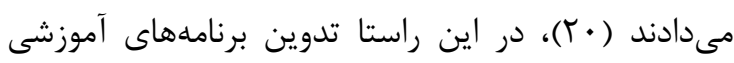
تئورى محور با هدف ارتقاى توانمندى زنان در بكاركيرى رفتارهاى غربالكرى ضرورى بهنظر مىرسد. بيش از نيمى از شركت كنند سبزيجات مصرف مى كردند و نزديك به نيمى از زنان نيز كمتر از r واحد در روز ميوه در سبد غذايى خود داشتند، شيبانى و همكاران نيز در يزوهش خود ميزان مصرف ميوه و سبزيجات در سبد غذايى زنان ايرانى را كمتر از ميزان توصيه شده كزارش كردند (Iآ)، Steinberg و همكاران در يزوهش متاآناليز خود، نقش موثر استفاده از ميوه و سبزيجات در بيشگيرى از سرطان در زنان تزارش نمودند (Tr) (T). با توجه به اهميت رزيم غذايى سالم در بيشگيرى از سرطان پِتان بهنظر مىرسد ضرورت تدوين سياستهاى

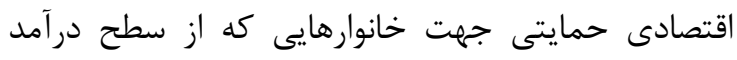
يايين برخوردار هستند، بسيار ضرورى است. 
بهنظر مىرسد زنان با سطح تحصيلات بالاتر آكاهى بيشترى نسبت به رفتارهاى ييشگيرى كننده از سرطان يستان دارند و به همين جهت در برنامهريزى مداخلات

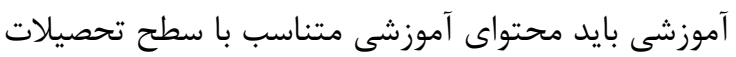
مخاطبين تنظيم كردد. بر اساس يافتههاى مطالعه ما سازههاى انخيزش محافظت، پاداش درك شده، شدت درك شده و آكاهى مهمهرين تعيين كننده رفتارهاى پيشخيرى كننده از سرطان يستان در ميان زنان بودند كه در مجموع ها ٪ واريانس تغيير رفتار را ي يشبينى نمودند، همسو با اين يافته در مطالعه

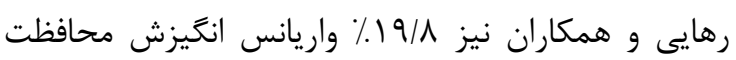
در برابر رفتارهاى پيشگيرى كننده از سرطان يستان توسط

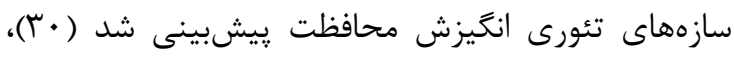
بهنظر مىرسد با هدف برجسته نمودن تبعات گسترده اين بيمارى و كاهش پِاداشهاى درونى و بيرونى ناشى از عدم انجام رفتارهاى محافظتى نظير احساس آسودگى و غيره، در اين راستا برنامهريزىهاى آموزشى در خصوص ارتقاى

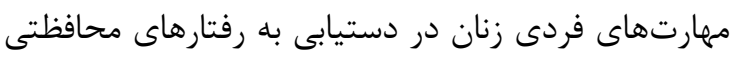
اثر بخش خواهد بود.

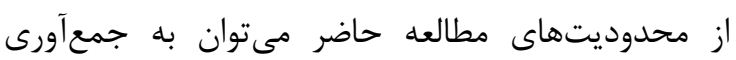
دادهها به روش خودَزارشدهى و غالب زنان مر اجعهكننده به مراكز خدمات جامع سلامت زنان خانهدار بودهاند كه قاعدتا معرف كل جامعه زنان نخواهد بود، پيشنهاد مى گردد در مطالعات ديكر زنانى كه به مراكز خدمات جامع سلامت مراجعه نمىكنند به لحاظ رفتارهاى ييشگيرى كننده از سرطان يستان بررسى گردند. از جمله نقاط قوت مطالعه حاضر مىتوان بررسى همزمان رفتارهاى

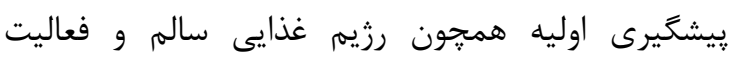
فيزيكى منظم در كنار رفتارهاى تشخيص زودرس نظير

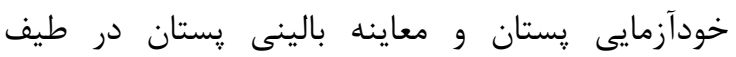
كستردهاى از گروههاى سنى زنان اشاره نمود.
معنادارى را درميان سازههاى تئورى انخيزش محافظت در

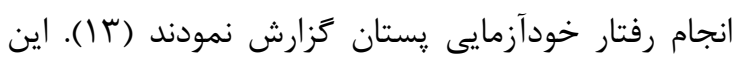

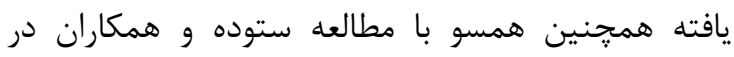
خصوص رفتارهاى پيشخيرى كننده از سرطان بود (ع).) طبيعى است زمانى كه زنان خود را مستعد ابتلا به سرطان

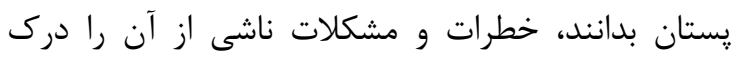
نمايند و به كارآمد بودن رفتارهاى سالم در ييشگيرى از سرطان يستان ايمان داشته باشند و از سويى ياداشها و هزينههاى ناشى از عدم انجام رفتار سالم در آنها كاهش يابد و به توانايى خود جهت انجام رفتارهاى محافظتى در

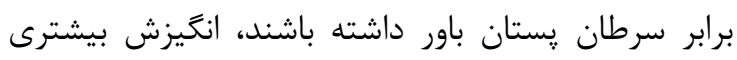

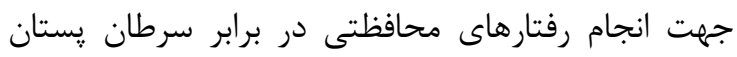

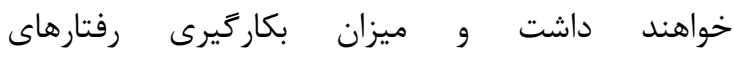
يشيشيرى كننده در آنها افزايش خواهد يافت. يافتهاى يزوهش حاضر نشان داد سطح تحصيلات زنان با رفتارهاى پيشگيرىكننده از سرطان קستان و سازهاى هزينه درك شده، ياداش درك شده و حساسيت درى شده همبستگى معنادارى داشت. اين يافته ها منطبق با يروهشهاى Al Arawi و همكاران (TV)، غفرانى يور و

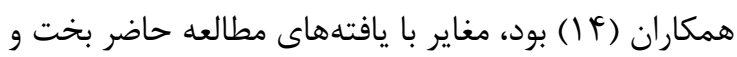
همكاران در يزوهش خود ارتباط معنادارى بين سطح تحصيلات با انخيزش محافظت و خودكار آمدى زنان معتاد در انجام تست پֶٍ اسمير جهت پِيشگيرى از سرطان دهانه رحم نشان دادند كه از جمله دلايل اين مغايرت ميتوان به تفاوت در حجم نمونه، عنوان يزوهش و نوع جمعيت مورد مطالعه اشاره نمود (YN) Curtin و همكاران در يزوهش خود اعلام كردند زنانى كه سطح تحصيلات كمترى داشتند، كمتر معتقد بودند كه فعاليت فيزيكى

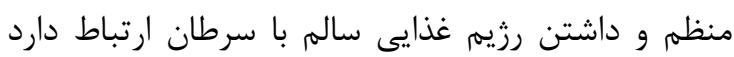
(Y9). در اين مطالعه نيز زنان با سطح تحصيلات بالاتر

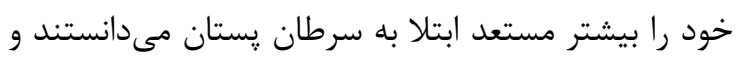
رفتارهاى محافظتى بيشترى نسبت به سرطان يستان انجام مى دادند و هزينه درك شده و پاداش درك شده كمترى براى انجام رفتارهاى غيرسالم در نظر كرفته بودند، 


$$
\begin{aligned}
& \text { تشكر و قدردانى } \\
& \text { تشكر ويزه از حمايت مالى دانشعاه علوم يزشكى خراسان } \\
& \text { شمالى و تمام زنانى كه در اين مطالعه شركت نمودند. } \\
& \text { تعارض منافع } \\
& \text { نويسندًان اعلام مىدارند كه هيجَّونه تعارض منافعى } \\
& \text { ندارند. }
\end{aligned}
$$

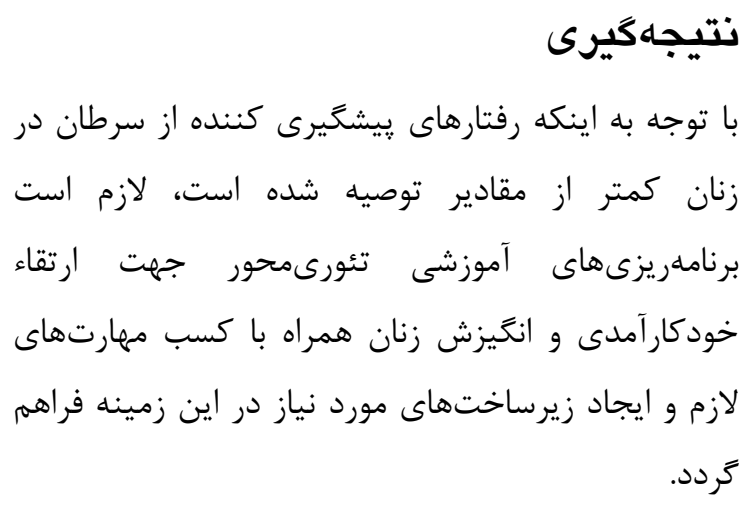

\section{References}

1. Taşhan ST, Derya YA, Uçar T, Nacar G, Erci B. Theory-based training to promote breast cancer screening among women with breast cancer worries: Randomized controlled trial. Sao Paulo Med J. 2020;138(2):158-6.

2. Chin JH, Mansori S. Theory of Planned Behaviour and Health Belief Model: females' intention on breast cancer screening. Cogent Psychol. 2019; 6(1):1647927.

3. Sung H, Ferlay J, Siegel RL, Laversanne M, Soerjomataram I, Jemal A, et al. Global cancer statistics 2020: GLOBOCAN estimates of incidence and mortality worldwide for 36 cancers in 185 countries. CA Cancer J Clin. 2021;71(3):209-49.

4. Shakery M, Mehrabi M, Khademian Z. The effect of a smartphone application on women's performance and health beliefs about breast self-examination: a quasi-experimental study. BMC Med Inform Decis Mak. 2021; 21(1):1-10.

5. Dilnaz F, Zafar F, Afroze T, Zakia UB, Chowdhury T, Swarna SS, et al. Mediterranean Diet and Physical Activity: Two Imperative Components in Breast Cancer Prevention. Cureus. 2021;13(8).

6. Vegunta S, Lester SP, Pruthi S, Mussallem DM. Effects of major lifestyle factors on breast cancer risk: impact of weight, nutrition, physical activity, alcohol and tobacco Mayo Foundation for Medical Education and Research. Breast Cancer Manag. 2020; 9(4): 1751-8.

7. Chen X, Wang Q, Zhang Y, Xie Q, Tan X. Physical activity and risk of breast cancer: a reports. Value Heal. 2019; 22(1):104-28.

8. Friedenreich CM. The role of physical activity in breast cancer etiology. In: Seminars in oncology. Elsevier. 2010; 37(3):297-302.

9. Seely JM, Alhassan T. Screening for breast cancer in 2018-what should we be doing today? Curr Oncol. 2018; 25(s1):115-24.

10. Mahmoudabadi M, Saeidifar A, Safizadeh H. Breast cancer screening behavior among nurses in kerman teaching hospitals and its relationship with the health beliefs model scales. 2018; 11(2):56-65.

11. Amani F, Fouladi N, Zakeri A, Tabrizian S, Enteshari-Moghaddam A, Barzegari S. Changing Trend of Breast Cancer in Ardabil Province, Iran by Age Group, Grading, and Gender during 2003-2016. Middle East J Cancer. 2021; 12(2):285-91.

12. Khodayarian M, Peyghambari F, Mazloomy Mahmoodabad S, Morowatisharifabad MA, Lamyian M. Development and Psychometric Evaluation of a Protection Motivation Theory-Based Scale Assessing the Adherence of Iranian Women Breast Cancer Prevention Behaviors. Iran Q J Breast Dis. 2019; 12(1):818.

13. Bashirian S, Barati M, Mohammadi Y, Moaddabshoar L, Dogonchi M. An application of the protection motivation theory to predict breast self-examination behavior among female healthcare workers. Eur J breast Heal. 2019; 15(2):90.

14. Ghofranipour F, Pourhaji F, Delshad MH. Determinants of breast cancer screening: meta-analysis of 38 cohort studies in 45 study 
Application of protection motivation theory. Int J Cancer Manag. 2020; 13(5):1-7.

15.Bashirian S, Barati M, Mohammadi Y, MoaddabShoar L, Dogonchi M. Evaluation of an Intervention Program for Promoting Breast Self-Examination Behavior in Employed Women in Iran. Breast Cancer Basic Clin Res. 2021; 15:1-11.

16. Rogers RW. A Protection Motivation Theory of Fear Appeals and Attitude Change1. J Psychol [Internet]. 1975;91(1):93-114. Available from: https://www.tandfonline.com/doi/full/10.1080/ 00223980.1975 .9915803

17. Haghighi F, Portaghali P, Javanbakht LR, Ghanbarzadeh N, Hosseini SM. Knowledge, attitude, and practice of female teachers regarding breast cancer screening in Birjand. Mod Care J. 2012; 9(2):146-55.

18. Alwan NAS, Al-Diwan JKA, Wafa'M A-A, Eliessa RA. Knowledge, attitude \& practice towards breast cancer \& breast self examination in Kirkuk University, Iraq. Asian Pacific J Reprod. 2012; 1(4):308-11.

19. Yeshitila YG, Kassa GM, Gebeyehu S, Memiah P, Desta M. Breast self-examination practice and its determinants among women in Ethiopia: A systematic review and metaanalysis. PLoS One. 2021; 16(1):e0245252.

20. Paknejad H. Knowledge, attitudes and practice of breast self-examination among over 20-year females in Tehran. Razi J Med Sci. 2019; 25(11):34-41.

21. Sheybani R, Hosseini Z, Davoodi SH, Aghamolaei T, Ghanbarnejad A. The effect of peer education intervention on consumption of fruits and vegetables in housewives. J Prev Med. 2018; 5(2):11-9.

22.Steinberg J, Yap S, Goldsbury D, NairShalliker V, Banks E, Canfell K, et al. Largescale systematic analysis of exposure to multiple cancer risk factors and the associations between exposure patterns and cancer incidence. Sci Rep. 2021; 11(1):1-14.

23.Ramazani Y, Karbasian N, Mobasheri M. A Survey on the State of Physical Activity
Among Middle-Aged Women in Health Center in Zarin Shahr City in Iran, fall 2016. JSKUMS. 2018; 20(1):15-21.

24. Darvishpour A, Vajari SM, Noroozi S. Can health belief model predict breast cancer screening behaviors? Open access Maced J Med Sci. 2018; 6(5):949.

25. Nahar VK, Black WH, Ford MA, Bass MA, Bentley JP, Johnson P, et al. Factors influencing sun protection behaviors among patients with skin cancer: an application of the information-motivation-behavioral skills model. J Dermatol Nurses Assoc. 2019; 11(5): 199-207.

26. Sotoudeh A, Mazloomy Mahmoodabad SS, Vaezi AA, Fattahi Ardakani M, Sadeghi R. Determining Skin Cancer Protective Behaviors in the Light of the Protection Motivation Theory among Sailors in BandarBushehr in the South of Iran. Asian Pacific J Cancer Prev. 2020; 21(12):3551-6.

27. Arawi A, Ahmed W, Shaman A, Salamh U, Albalawi WAM, Siddhachettiar PA, et al. Association of Demographic Variables with the Awareness of Type 2 Diabetes Mellitus Patients (T2DM) among the Northwest Population in Saudi Arabia. J Diabetes Res. 2020 ;2020:1-9.

28. Bakht $\mathrm{r}$, shobeiri f, roshanaei g, fakouri e. The factors affecting cervical cancer screening among addicted women of hamedan in 2015: on the basis of protection motivation theory model. 2017; 4(2): 68-80.

29. Curtin KD, Thomson M, Nykiforuk CIJ. Who or what is to blame? Examining sociodemographic relationships to beliefs about causes, control, and responsibility for cancer and chronic disease prevention in Alberta, Canada. BMC Public Health. 2021; 21(1):1-12.

30. Rahaei Z, Ghofranipour F, Morowatisharifabad MA, Mohammadi E. Determinants of cancer early detection behaviors: application of protection motivation theory. Heal Promot Perspect. 2015; 5(2):138. 